\title{
Study on Three-dimensional Electrolysis Process of Malachite Green Waste Water
}

\author{
Jinhua Yin, Qingsheng Zhao \\ School of Qingdao University of science\& technology ,Shandong ,China
}

Keyword: Three-dimensional Electrolysis; Malachite Green Waste Water

\begin{abstract}
This study focused on electrolysis of refractory malachite green waste water with three-dimensional electrode. In this research, high-purity graphite was used as the cathode, titanium-plating metal mesh as the anode, while coal column, coconut shell granular activated carbon and catalytic Titanium dioxide $\left(\mathrm{TiO}_{2}\right)$ modified activated carbon as particle electrode, respectively. The electrolytic condition was set as follows: $\mathrm{pH}=6$, the voltage of $8 \mathrm{v}$, an aeration rate of $20 \mathrm{~L} / \mathrm{h}$, an electrolyte concentration of 0.1 $\mathrm{mol} / \mathrm{L}$, an electrolysis time of $2 \mathrm{~h}$, and the highest chemical oxygen demand (COD) degradation rate of malachite green was up to $99 \%$. That $\mathrm{TiO}_{2}$ modified activated carbon served as particle electrode can increase the degradation effect and the current efficiency. Ultraviolet (UV) analysis showed that the structure of malachite green was altered to achieve an effective degradation during the electrolysis process with three-dimensional electrode.
\end{abstract}

\section{INTRODUCTION}

Electrochemical degradation of organic waste water was widely applied due to its outstanding merits, such as high efficiency, no secondary pollution, etc[Arjunan,2013][Jeon J R,2009]. Three-dimensional electrolysis is formed by filling the traditional two-dimensional electrolytic cell with granular or other clastic working electrode materials (for instance, activated carbon) and electrizing the filler to make it a novel electrode, on the surface of which electrochemical reaction takes place to produce substances with a strong oxidizing property, such as $\mathrm{H} 2 \mathrm{O} 2 \mathrm{or} \mathrm{OH} \cdot$, resulting in oxidative decomposition of the organics and other substances required to be removed in the waste water[Gomez L V,2006]. Compared with the traditional flat two-dimensional electrolysis, the three-dimensional electrode possesses a reaction zone of electrochemical reactor wide distributed on the surface of three dimensional space of the whole bed scale, which makes it easy to realize continuous operation under different current densities, especially suitable for reaction systems with low reaction rate or small limiting current density. Generally, dye waste water is refractory. Malachite green has the typical structure of triphenylmethane dyes and possesses potential carcinogenic, teratogenic and mutagenic effects. Conventional biochemical treatment methods for the COD removal rate of waste water is $60-70 \%$, while the removal rate of the biochemical oxygen demand(BOD) is just approximately 50\%[Jin Z F,2010][ Chen C H,2010].

Three-dimensional electrolysis of malachite green waste water, with coal column, coconut shell granular activated carbon and catalytic $\mathrm{TiO} 2$ modified activatedcarbon as particle electrode, respectively.

\section{MATERIALS AND METHODS}

\subsection{Materials and apparatus}

Reagent: malachite green waste water (a concentration of $250 \mathrm{mg} / \mathrm{L}$ ), activated carbon, potassium dichromate, concentrated sulfuric acid, sodium sulfate, silver sulfate, potassium hydrogen phthalate, isopropyl alcohol, TiO2.

Electrolytsis apparatus: graphite sheet as the cathode, titanium-plating metal mesh as the anode, the size of both is a square with a side length of $5 \mathrm{~cm}$, and an electrode plates space of $8 \mathrm{~cm}$. Third electrode is particle electrode composed of coal column, coconut shell granular activated carbon and catalytic TiO2 modified activated carbon, respectively. TiO2 modifying activated carbon process: tetrabutyltitanate, isopropyl alcohol and distilled water were successively added into 
activated carbon, and followed with stirring for 10 - $20 \mathrm{~min}$, vacuum drying under $80{ }^{\circ} \mathrm{C}$ for $10 \mathrm{~h}$, and roasting $3 \mathrm{~h}$ under $450{ }^{\circ} \mathrm{C}$. Particle electrode itself does not have the ability to degrade the organics, therefore, particle electrode was saturated with waste water to be degraded before use in order to avoid the influence of adsorption on the degradation efficiency.

With coconut shell granular activated carbon as particle electrode, the electrolysis condition was optimized through orthogonal test and set as follows: 6 for $\mathrm{pH}$ value 6 , the voltage of $8 \mathrm{v}$, an aeration rate of $20 \mathrm{~L} / \mathrm{h}$, an electrolyte concentration of $0.1 \mathrm{~mol} / \mathrm{L}$ and an electrolysis time of $2 \mathrm{~h}$.

\subsection{Methods}

Firstly, draw the standard curve between COD and transmissivity with potassium hydrogen phthalate as standard solution. $0.8502 \mathrm{~g}$ potassium hydrogen phthalate was weighed out and dissolved in $1000 \mathrm{~mL}$ distilled water to get a solution with a COD concentration of $1000 \mathrm{mg} / \mathrm{L}$. Afterwards, 0, 1, 5, 10, $15 \mathrm{~mL}$ of the above mentioned solution were respectively measured and put into $100 \mathrm{~mL}$ volumetric flasks and diluted to the scale, to obtain the COD concentrations of $0.0,10$, 50, $100,150 \mathrm{mg} / \mathrm{L}$. $\quad$ l. $0 \mathrm{~mL}$ of masking agent, $1.0 \mathrm{~mL}$ of digestion liquid and $3.0 \mathrm{~mL}$ of catalyst were successively added and thoroughly mixed in tightly sealed tubes. The heating tubes were taken out to chill down after 15 min digestion reaction under $165^{\circ} \mathrm{C}$.

The solutions were put into the cuvette and measured at $445 \mathrm{~nm}$ with blank solvent for reference. The standard curve was shown in Figure 1.Then the absorbance of waste water was measured with UV analysis after electrolysis treatment to obtain the COD value through the standard curve, which indicated the degradation efficiency of waste water.

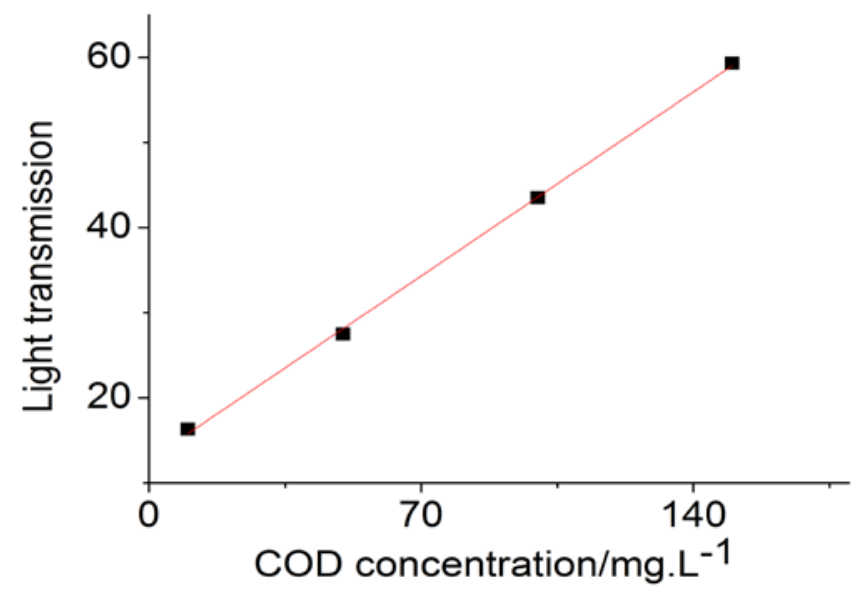

Figure. 1 The standard curve of COD and light transmission

$$
\mathrm{Y}=12.70722+0.00584 \mathrm{X}
$$

This equation (Eq. (2.1)) was the description of the relationship between COD concentration and light transmission, $\mathrm{X}$ represented the COD concentration and Y represented the light transmission. The Adj.R-square of this equation was 0.99893, so the standard curve we got was ideal.

The concentration of malachite green was measured though the chroma of waste water. Standard malachite green solutions with a series concentration of $0,5,10,20,30,40 \mathrm{mg} / \mathrm{L}$ were prepared and measured at $615 \mathrm{~nm}$. The standard curve between absorbance and concentration was drawn and shown in Figure 2. 


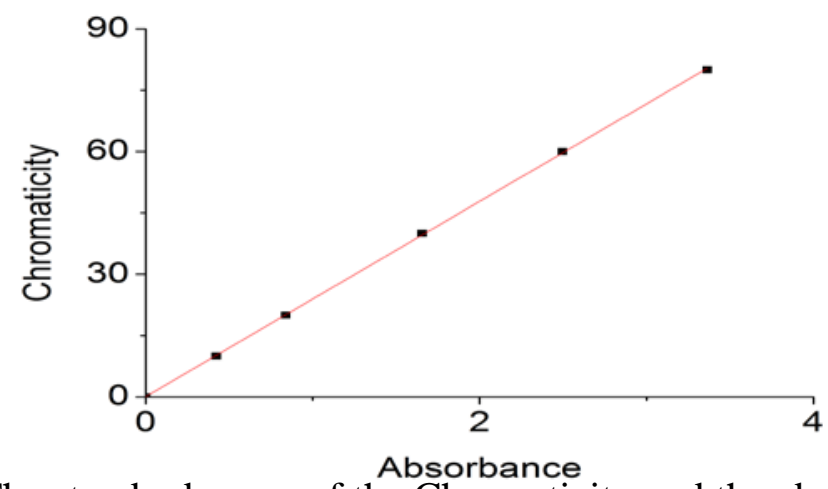

Figure.2 The standard curve of the Chromaticity and the absorbance

$\mathrm{Y}=0.0806+23.87107 \mathrm{X}$

This equation (Eq. (2.2)) was the description of the relationship between absorbance and chromaticity, $\mathrm{X}$ represented the absorbance and $\mathrm{Y}$ represented the chromaticity. The Adj.R-square of this equation was 0.99987 ., so the standard curve we got was also ideal.

The concentration of malachite green was obtained by measuring the absorbance of the degraded waste water. In addition, the structure change of malachite green in waste water was detected through UV spectrum scanning.

\section{RESULTS}

Experiments were carried out to investigate the three-dimensional electrolysis of malachite green waste water when different types of activated carbon as the particle electrode and the results were shown as follows. The current in the electrolysis progress were $0.06 \mathrm{~A}$ and $0.1 \mathrm{~A}$ separately when TiO2 modified coconut shell granular activated carbon and coconut shell granular activated carbon without any modification served as the particle electrode, and the COD degradation effect was shown in Figure 3.

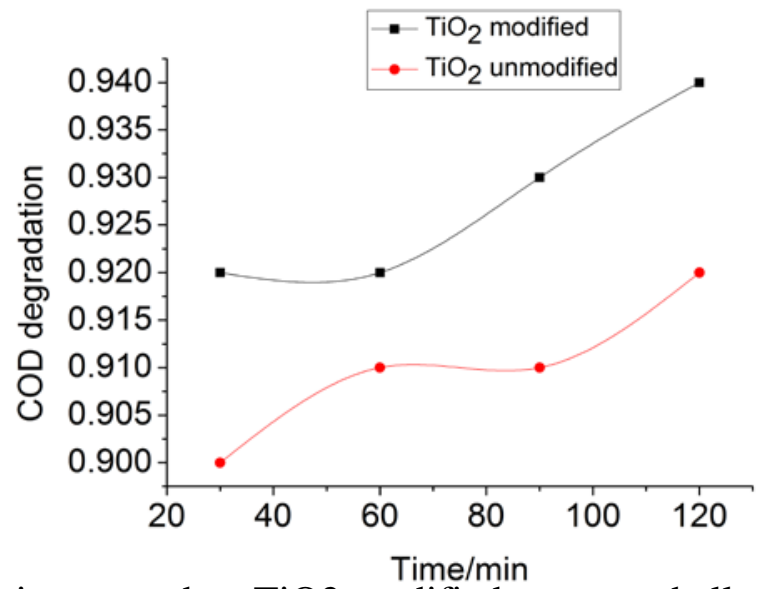

Figure.3 The degradation rate when TiO2 modified coconut shell granular activated carbon and coconut shell granular activated carbon without $\mathrm{TiO} 2$ as the particle electrode

In addition, the current were $0.075 \mathrm{~A}$ and $0.15 \mathrm{~A}$ respectively when $\mathrm{TiO} 2$ modified columnar activated carbon and columnar activated carbon applied as the particle electrode, and the COD degradation effect was shown in Figure 4. 


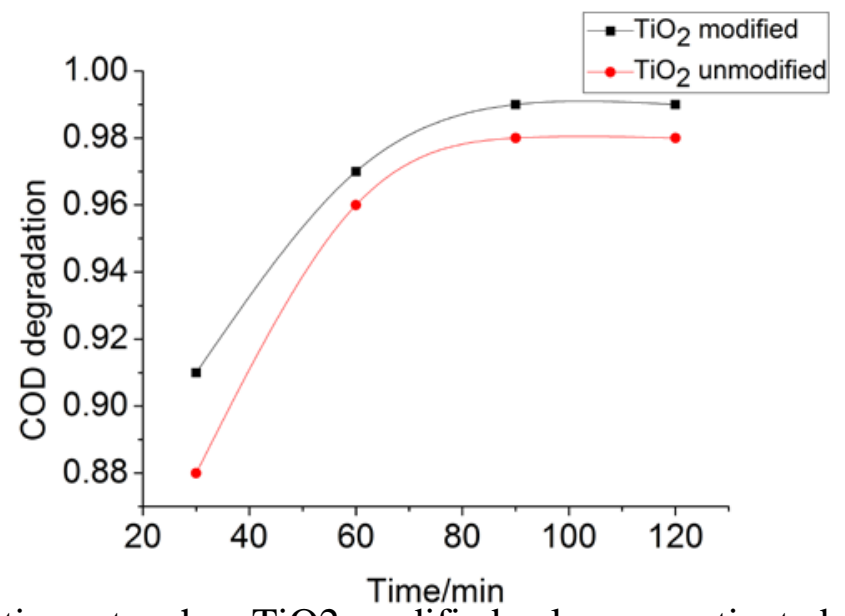

Figure.4 The degradation rate when TiO2 modified columnar activated carbon and columnar activated carbon without $\mathrm{TiO} 2$ as the particle electrode

According to the results, both the electrolysis efficiency and degradation rate of columnar activated carbon were lower than those of coconut shell granular activated carbon which also showed a smaller degradation current. Furthermore, TiO2 modified coconut shell granular activated carbon presented the highest electrolysis efficiency and degradation rate. COD degradation rate of TiO2 modified coconut shell granular activated carbon was up to $99 \%$ while the degradation current is merely 0.06 A which was $40 \%$ lower than that of the common coconut shell granular activated carbon. It was due to that big specific surface area could enhance the electrolysis efficiency and the specific surface areas of coconut shell granular activated carbon and columnar activated carbon were $1145.1 \mathrm{~m} 2 / \mathrm{g}$ and $1145.1 \mathrm{~m} 2 / \mathrm{g}$, separately. Moreover, loaded TiO2 possesses catalytic action, which is in favor of improving electrolysis efficiency and the current utilization.

Malachite green waste water was electrolyzed with TiO2 modified coconut shell granular activated carbon as the particle electrode. The samples were taken out every 15 min and scanned with UV analysis in the range of $200-800 \mathrm{~nm}$. The result was shown in Figure 5. Along with the electrolysis progress, malachite green was gradually degraded and the intensity of its three characteristic absorption peaks in the range of 270 - $800 \mathrm{~nm}$ were decreased, which demonstrated the changes occurred in the molecular structure of malachite green and the refractory structures, like benzene ring, were destroyed.

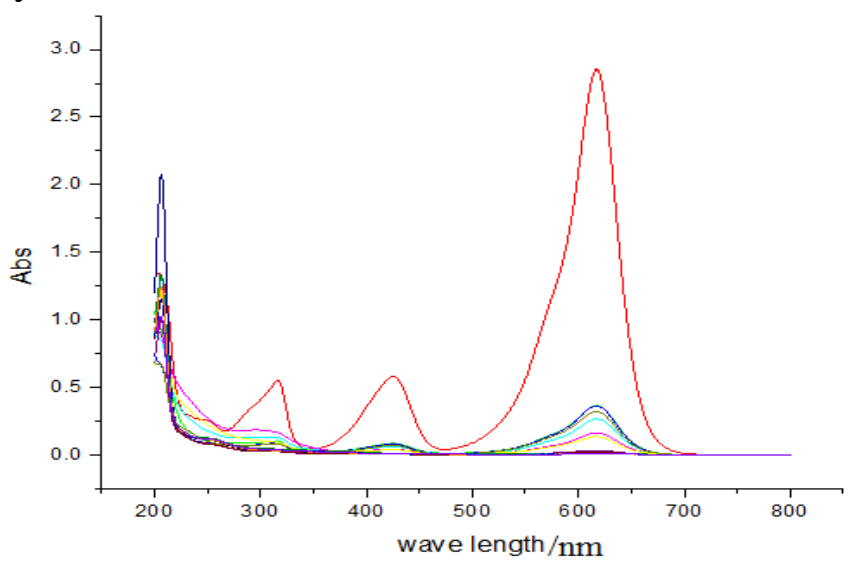

Figure.5 The result of UV spectrum scanning

\section{CONCLUSION}

(1) Applied as the particle electrode in the three-dimensional electrolysis of malachite green waste water, coconut shell granular activated carbon showed higher electrolysis efficiency and degradation rate than those of columnar activated carbon. TiO2 modified coconut shell granular activated carbon presented the highest electrolysis efficiency and degradation rate, COD 
degradation rate of which was up to $99 \%$ while the degradation current is merely 0.06 A which was $40 \%$ lower than that of the common coconut shell granular activated carbon.

(2) Based on the result of UV analysis, the molecular structure of malachite green was altered and the refractory structures were destroyed in the process of three-dimensional electrolysis.

\section{Reference}

[1] Arjunan et al. 2013, A review on Fenton and improvements to the Fenton process for wastewater treatment. Journal of Environmental Chemical Engineering, 2(2014 ):557-572

[2] Jeon J R, et al. 2009,Use of grape seed and its natural polyphenol extracts as a natural organic coagulant for removal of cationic dyes [J]. Chemosphere, 77:1090-1098.

[3] Gomez L V, et al. 2010, Preparation and characterization of RuO2- IrO2- SnO2 temary mixtures for advanced electrochemical technology. Applied Catalysis B: Environmental, 2006,6 7:34-40 .

[4] Jin Z F, et al. Experimental study on pressurized activated sludge process for high concentration pesticide wastewater. Journal of Enviromental Sciences, 22(9):1342-1347

[5] Chen C H, et al. 2010, Partial degradation mechanisms of malachite green and methyl violet B by Shewanella decolorationis NTOU1 under anaerobic anaerobic conditions. Journal of Hazardous Materials, 177:281-289. 